\title{
Introduction: Literacies and autonomy of the advanced language learner
}

\author{
Nikolay Slavkov \\ nikolay.slavkov@uottawa.ca \\ UNIVERSITY OF OTTAWA
}

The present volume contains ten articles related to the literacies and autonomy of the advanced language learner, which was the overarching theme of the 2014 CCERBAL Conference organized by the OLBI and hosted by the University of Ottawa. This theme was implemented in various ways and within various scholarly domains during the conference, representing work related to the main pillars of the OLBI's expertise: language teaching, language policy, language assessment and technology-enhanced language learning. Similarly, the articles in this issue revolve around these core areas and represent a diversity of perspectives generated by both established researchers and emerging scholars. Some of the articles draw on completed research projects, others report on work in progress or pilot studies, and still others are based on pedagogical workshops. This mix of approaches and perspectives exemplifies the dynamic nature of the field and is indicative of the vibrant research and teaching culture fostered by the OLBI and its research centre, the CCERBAL.

The volume is introduced by a lead article, and the rest of the submissions are divided into two sections: Research and Pedagogical Perspectives. The Research section contains articles based on empirical studies, while the Pedagogical Perspectives section contains articles based on reflections on classroom practices or teaching workshops. Some of the articles contain elements from both categories, which highlights the interconnectedness and, in some cases, fusion of research and practice. This invites us to pause for a moment and rethink some of the traditional lines that we are used to drawing in conceptualizing scholarly communication.

\section{Lead article}

The issue begins with the lead article, "Le développement de l'autonomie dans l'apprentissage des langues et cultures étrangères: le cas de l'Université de Strasbourg", by one of the plenary speakers at the conference, Nicole Poteaux. 
A well-known scholar in the field of learner autonomy, Poteaux relates rich experiences and examples from her long-standing work in this domain, focusing on a paradigm shift from teacher-centered to learner-centred and self-directed approaches to language learning. In this shift, learners emerge from their traditionally passive role of receivers of instruction and become responsible autonomous agents, empowered by a wide range of choices in terms of resources, modalities and interlocutors. The language teacher, on the other hand, has also acquired a new role: that of a listener, an attentive observer and a counselor able to provide non-prescriptive advice and engage in pedagogical dialogue with the learners.

\section{Research}

The first article in this section, "Les compétences en français: Agentivité et motivation des étudiants universitaires", by Krystyna Baranowski, also echoes the theme of autonomy. Baranowski relates the preliminary results of a series of interviews with Francophone, Anglophone and Allophone students at a small French-speaking university in Manitoba. In the context of students reporting challenges with their French language proficiency, Baranowski finds that incorporating elements of the Canadian Language Portfolio for Teachers (CASLT/ACPLS, 2010) contributes to a growing sense of autonomy and linguistic responsibility, which ultimately has the potential of providing long-lasting benefits to the learners.

The next article, "Engaging the hidden curriculum within the Canadian Language Benchmarks (2000 and 2012) as a complicated conversation", by Douglas Fleming, questions the extent to which an assessment framework can be viewed as separate from a curriculum. The author offers a discussion of the Canadian Language Benchmarks (Pawlikowska-Smith, 2000; Hajer and Kaskens, 2012) and argues that immigrant English language learners may be acculturated in specific ways through language instruction based on the CLB. $\mathrm{He}$ calls for a broadened perspective on language teaching and assessment that includes more overtly the values of citizenship and equity.

The third article in this section, "Developing autonomy through awareness of textual features in academic texts", by Hedy McGarrell, focuses on academic writing and reports on an empirical study of university students using the Corpus of Contemporary American English (COCA) (Davies, 2008) and the Compleat Lexical Tutor (Cobb, 2015). Based on an analysis of the texts created by the students as well as participant and teacher interview data, the author found that the use of corpus tools is beneficial with regard to awareness of lexical conventions and sentence structure.

The next article, "Canadian English teachers: Volunteering to teach their mother tongue in a foreign country", by Gloria Romero, takes us to Chile and 
offers a qualitative research perspective on Canadian volunteers in local public schools. The author uses experiential and sociocultural perspectives (Dewey, 1938; Vygotsky, 1978) and discusses themes related to both the volunteers' instructional practices and personal experiences in their new environments.

The section ends with "La place de la compétence paraphrastique dans le Cadre européen commun de référence pour les langues" by Alexandra Tsedryk. Paraphrasing competence is an important aspect of language use by learners not only as an indicator of lexical and grammatical richness but also in terms of effective communication. The author argues that even though the concept of reformulation is embedded in the CEFR (Council of Europe, 2001), according it a more prominent role may be beneficial for learners.

\section{Pedagogical perspectives}

The first article in this section, "Towards narrative-centred digital texts for advanced second language learners", by Nolan Bazinet, brings us to the domain of English language teaching in Quebec and to the use of technology and new media in the classroom. Bazinet draws on his experiences as a college-level language teacher and relates new ways to motivate students, particularly when competing for "the students' attention with their electronic devices" (p. 86). The author explores narrative-focused digital games as an instructional tool and argues that such games can foster use of figurative and culturally imbued language in autonomous settings by learners at the advanced levels.

Also investigating the use of new media and technologies in the classroom, in "Reaping the benefits of using Twitter in advanced language learning", Stacia Johnson draws links between Vygotskian social constructivism (Vygotsky, 1978) and microblogging. The author relates classroom practices from a French as a second language high-school level course and discusses potential benefits with regard to student engagement, collaboration and overall feeling of connectedness that ultimately help foster language learning.

The next article, "Advanced English language acquisition and application in specialized subject areas", by Lucia Taylor, draws on a sociological framework and proposes a view of second language teaching focused on specialized subject areas. She argues that soft skills related to appropriate language use for efficient communication are as important as specialized content knowledge and know-how in order for English language learners to be able to integrate successfully into the Canadian labour market.

Continuing with the theme of sociocultural and sociolinguistic literacy, the volume ends with "Pour que les étudiants de FLS comprennent et participent à la francophonie canadienne", by Laurence Thibault, Marie-Claude Dansereau and Sylvie Lamoureux. This article addresses the need for future French as a second language teachers to develop literacies in Canada's Fran- 
cophone communities. Drawing on previous research, the authors discuss two types of pedagogical practices, one with regard to intercultural competence, and one with regard to an understanding of local language varieties and their symbolic status.

\section{References}

Association canadienne des professeurs de langue seconde/Canadian Association of Second Language Teachers (ACPLS/CASLT). 2010. Portfolio canadien des langues pour enseignants. Ottawa: ACPLS/CASLT.

Cobb, T. 2015. The Compleat Lexical Tutor, v. 8. Disponible à: www.lextutor.ca.

Council of Europe. 2001. Common European framework of reference. Paris: Didier. Available at: www.coe.int//dg4//inguistic/Source/framework_en.pdf.

Davies, M. 2008-. The Corpus of Contemporary American English: 450 million words, 1990-present. Available at: corpus.byu.edu/coca/.

Dewey, J. 1938. Experience and education. New York: Collier.

Hajer, A. and A. Kaskens. 2012. Canadian language benchmarks 2012. Ottawa: Centre for Canadian Language Benchmarks.

Pawlikowska-Smith, G. 2000. Canadian language benchmarks 2000. Ottawa: Centre for Canadian Language Benchmarks.

Vygotsky, L.S. 1978. Mind in society: The development of higher psychological processes. Cambridge, MA: Harvard University Press. 